\title{
LUT
}

Lappeenranta

University of Technology

\section{Performance enhancement of thin-film composite membranes in water desalination process by wood sawdust} Namaghi Hamed Azizi, Asl Ali Haghighi, Chenar Mahdi Pourafshari, Hesampour
Mehrdad, Pihlajamäki Arto, Mänttäri Mika

This is a Post-print version of a publication published by Wiley

in Polymers for Advanced Technologies

DOI: $10.1002 /$ pat.4712

Copyright of the original publication: () 2019 John Wiley \& Sons, Ltd.

Please cite the publication as follows:

Namaghi H. A., Asl A. H., Chenar M. P., Hesampour M., Pihlajamäki A., Mänttäri M. (2019). Performance enhancement of thin-film composite membranes in water desalination process by wood sawdust. Polymers for Advanced Technologies, Vol 30, Issue 11. p. 2802-2818. DOI: 10.1002/pat.4712 
Performance enhancement of thin film composite membranes in water desalination process by wood sawdust

Hamed Azizi Namaghi ${ }^{1,2}$, Ali Haghighi Asl ${ }^{1, *}$, Mahdi Pourafshari Chenar ${ }^{3,4}$, Mehrdad Hesampour $^{5}$, Arto Pihlajamäki², Mika Mänttäri ${ }^{2}$

${ }^{1}$ Faculty of Chemical, Petroleum and Gas Engineering, Semnan University, Semnan, Iran

${ }^{2}$ LUT School of Engineering Science, Lappeenranta University of Technology, P.O. Box 20, 53850 Lappeenranta, Finland

${ }^{3}$ Chemical Engineering Department, Faculty of Engineering, Ferdowsi University of Mashhad (FUM), Mashhad, Iran

${ }^{4}$ Membrane Processes and Membrane Research Center, Faculty of Engineering, Ferdowsi University of Mashhad (FUM), Mashhad, Iran

${ }^{5}$ Kemira Oyj, R\&D Center, Espoo, Finland

\section{ABSTRACT}

In this study, polysulfone/wood sawdust (PSf/WSD) mixed matrix membrane (MMM) was prepared as a novel substrate layer of thin film composite (TFC) membrane in water desalination. The polyamide (PA) layer was formed on the surface of MMM via interfacial polymerization (IP) to prepare TFC membrane. The main aim was to evaluate how different amount of WSD (0-5 wt.\%) and PSf concentration (12-16 wt.\%) in the porous substrate affect the separation properties of the final TFC membranes. Furthermore, the physicochemical and morphological properties of substrates and resultant TFC membranes were investigated with various analytical techniques. The results showed that the WSD significantly affected morphology, overall porosity, mechanical stability and also pure water permeability (PWP) of MMMs. Morphological and wettability studies demonstrated that the addition of small amount of WSD $(\leq 1 \mathrm{wt} . \%)$ in the casting solution resulted

${ }^{*}$ Corresponding author: Tel.: +98 23 33654287; fax: +98 23 33654281, E-mail: ahaghighi@ semnan.ac.ir (A. Haghighi Asl). 
in more porous but similar hydrophobic substrates. While, high loading ( $\geq 2$ wt. $\%$ ) of WSD not only changed the substrate wettability and morphology, but also increased and decreased the swelling and mechanical properties of substrate layer, respectively. Therefore, PA layer formed thereon displayed extensively varying film morphology, interfacial properties, and separation performance. Based on approximately stable permeate flux (ASPF) and apparent salt rejection efficiency (ASRE), the best TFC membrane was prepared over the substrate with 12-14 wt.\% PSf and around $0.5-1$ wt.\% WSD. A notable improvement in permeate flux (11\%) was obtained by adding a small amount of sawdust.

Keywords: Mixed matrix membrane; Wood sawdust; Substrate modification; PA-TFC membrane; Desalination

\section{Introduction}

A great advantage of TFC membrane technology is that the characteristics of the ultra-thin barrier layer and the porous substrate can be independently optimized with respect to structure, stability, and performance [1-3]. Consequently, various parametric studies have been investigated by researchers to improve the performance of TFC membranes via optimizing the porous substrate and top selective layers. Although the role of PA as the top selective layer is very bold, especially in solute separation and fouling reduction, understanding how structural and physicochemical characteristics of the substrate influence performance is vital to further development of membranes designed for reverse osmosis (RO) process. In particular, the PA film thickness, roughness, morphology, interfacial properties and finally performance are significantly related to the morphology, physicochemical properties, overall porosity, pore size and also wettability of 
substrate $[1,3,4]$. Several significant systematic investigations [1-6] have accordingly attempted to explain the relationship between substrate structure and final TFC membrane performance.

Most of above mentioned studies have only focused on the interaction between the non-selective pure microporous substrate and ultra-thin selective barrier layer. Various strategies have been proposed to modify the substrate layer before PA film is deposited on the porous substrate layer (PSL). In one conventional strategy, a mixed matrix UF membranes with different morphologies, pore sizes, wettability and mechanical properties can be produced by embedding a filler material within a polymer matrix [7]. Accordingly, several systematic reviews of substrate modification have been undertaken. A comprehensive review of MMMs was recently published by Qadir et al. [8]. It not only covers the challenges and technological issues regarding MMMs in addition to future recommendations, but also categorizes MMMs based on their filler types for their applications in water purification industry. In another major study, Yin et al. [9] summarized the recent scientific and technological advances in the development of nanocomposite membranes for water treatment. Collectively, both reviews outline a significant role for MMMs in TFC membrane preparation. In this regards, the use of nanoparticles based on materials such as $\mathrm{SiO}_{2} / \mathrm{Zeolite}$ [10], graphene oxide [11], multi-walled carbon nanotubes [12], and Zeolite A [13] have already been explored in PSf polymeric membranes. Therefore, the application of nanoparticles as an additive in preparation of TFC membrane for desalination has opened a new emerging area of research.

Far little attention has been paid to use sawdust in scientific applications, especially membrane separation processes so far. An effort has been made by Bose et al. [14] in which they applied five different size ranges of screened sawdust as a pore-former in ceramic membrane manufacturing for controlling membrane morphology and demonstrating the change in physical behavior during entire sintering steps. They observed that incorporation of sawdust as a pore-former in the 
fabrication of ceramic membrane is well appreciable. In one well-known recent experiment, Miao et al. [15] also utilized tetrabutylammonium acetate (TBAA) and dimethyl sulfoxide (DMSO) to dissolve wood powder directly. Also, they applied dissolution-extraction-reconstitution cyclic process for three times to achieve cellulose-rich extraction residue. The residual cellulose from each cycle were used in membrane preparation. Their results showed that the membrane with less lignin were found to be more uniform and flexible. In addition, the tensile and hydrophilic properties of the as-prepared membranes were promoted via partial separation of lignin from wood. In follow-up studies [16-18], Vilakati and coworkers studied the effects of lignin as a natural polymer additive on the properties of UF membranes. Their morphological results showed that the overall porosity of the bottom sublayer increased with the use of lignin. Also, membranes modified with lignin were found to have more water uptake than virgin membrane. In addition, large number of hydroxyl groups in the lignin polymer improved the interaction of PSf and lignin through hydrogen bonding, resulting in the fabrication of thermally stable membranes.

Anyhow, to the best of authors' knowledge, the use of sawdust in polymeric membrane preparation and its application in desalination process with TFC membrane has not been investigated. Consequently, the use of WSD as a modifier in preparation of PSL of TFC membrane to alter substrate membrane morphology, demonstrate the change in its physicochemical properties as well as performance improvement of resulting TFC membranes, are the originality and ultimate goal of the present study. Hereupon, the influence of grinded WSD loading and PSf concentration on PSL and TFC membranes were characterized using qualitative and quantitative approaches such as attenuated total reflection Fourier transform infrared (ATR-FTIR) spectroscopy, particle size distribution (PSD), scanning electron microscopy (SEM), static water contact angle (CA), maximum swelling degree (MSD), and mechanical strength. Afterwards, the performance of the 
resulting TFC membranes were tested in a cross-flow experimental setup. It should be noted that in replicated trials, data are expressed as the mean \pm standard deviation.

\section{Materials and methods}

\subsection{Chemicals}

The non-woven polyester (PET, grade 3329) support material was provided from Ahlstrom Filtration LLC. PSf resin (approx. M.W. 60000 g.mol-1, density: 1.24 g.cm ${ }^{-3}$ ) was provided by Acros. N-Methyl-2-Pyrrolidone (NMP) and N,N-Dimethylformamide (DMF) solvents purchased from Merck. The main reactive monomers including 1,3,5-benzenetricarbonyl trichloride (TMC, purity 98\%) and 1,3-phenylenediamine (MPD, purity 99\%) were supplied by Sigma-Aldrich. The organic solvent, n-Hexane (supplied from Rathburn Chemicals) was used to prepare the TMC solution. All chemicals and reagents were technical grade and used without further purification. For the TFC membrane performance tests, $20 \mathrm{~g}$ of sodium chloride ( $\mathrm{NaCl}$, crystals from Merck)

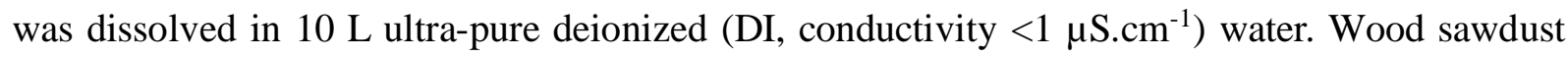
macroparticles is taken from a local sawmill factory.

\subsection{WSD preparation}

WSD samples were sieved to remove the large lumps. The fine particles of WSD were placed inside O-type grinding jar of the Retsch planetary ball mill PM 100 bench-top unit. The samples were placed into liquid nitrogen (LN) for 2 minutes before ball mill processing. Afterwards, the jar was filled with WSD (one-tenth (almost $6 \mathrm{~g}$ ) of the jar volume) and grinding balls. In order to investigate the impact of grinding time to WSD particle size, it was preset digitally at 10, 20 and 30 minutes. Finally, to remove impurities and also change in physical properties, WSD samples were thoroughly and successively washed with DI water, $0.1 \mathrm{M}$ nitric acid, DI water, $0.1 \mathrm{M}$ sodium 
hydroxide solution, DI water, and finally dried at $50{ }^{\circ} \mathrm{C}$ for a day and stored in a sealed container prior to the experiment.

\subsection{Membrane preparation}

Asymmetric flat sheet PSf/WSD substrates were prepared via non-solvent induced phase separation (NIPS) method. In this regard, various loading of WSD particles including $0.5,1,2$, and 5 wt.\% (based on the weight ratio of WSD to PSf polymer) were firstly added to NMP solvent and stirred for about $2 \mathrm{~h}$. In order to better identify the effect of adding WSD in the polymeric solutions, various specified amounts of PSf $(12,14$, and 16 wt.\%) were gradually added to the pervious mixture. At room temperature, the mixture is stirred as long as the polymer is completely dissolved. The homogeneous casting solution was laid aside to degas for $3 \mathrm{~h}$. Since seepage of the casting solution through the PET layer was observed, PET support was dipped into DI water and DMF solvent solution (containing 60-65 vol.\% water) for 1 minute. The polymeric solutions were manually cast on (i) non-woven PET for permeation tests and (ii) glass plate for characterization tests, using man-made film applicator with a casting solution thickness of $200 \mu \mathrm{m}$ and then immediately immersed in the coagulation bath containing DI water at temperature around $20{ }^{\circ} \mathrm{C}$. After initially phase separation, the membranes were stored in water extraction bath for a day to leach out the residual solvents completely.

The preparation process of PA layer was performed in accordance with previous reported procedure based on IP process [19]. Accordingly, the ultimate optimum conditions for significant factors were selected in which the permeate flux and salt rejection were maximized simultaneously. Hence, MPD soaking time and IP time were considered 4 and 1.5 minutes, respectively. The concentration of MPD and TMC solutions were selected $2 \% \mathrm{w} / \mathrm{v}$ and $0.1 \% \mathrm{w} / \mathrm{v}$, respectively. Finally, the resultant TFC membrane were cured at oven temperature of $78{ }^{\circ} \mathrm{C}$ for 4 
minutes. With respect to the polymer concentration and WSD loading, the resultant substrate and TFC membranes were denoted PSL-PSf/WSD and TFC-PSf/WSD i.e. PSL-16/00, PSL-16/0.5, PSL-16/01, ..., PSL-12/02, PSL-12/05 and TFC-16/00, TFC-16/0.5, TFC-16/01, .., TFC-12/05.

\subsection{Membrane characterization}

ATR-FTIR spectrometer (Perkin Elmer Frontier system with universal ATR module, Diamond crystal, USA) was used to characterize the presence of various functionalized groups in membrane samples. FTIR spectra were collected in absorbance mode over a wavenumber range of 4000-400 $\mathrm{cm}^{-1}$. At least three different locations of membrane samples were randomly selected and the average of those has been considered. The membrane samples were air dried before IR analysis.

In order to have a proper estimation of WSD particle size properties (volume density and number density) was measured by Mastersizer 3000 laser particle size analyzer (Malvern Instruments, MAL1097940, United Kingdom) in a standard dispersant pure solvent (ethanol). Laser diffraction technique is used to measure PSD from 0.1 to $1000 \mu \mathrm{m}$.

The surface and cross-section morphology of substrates and PA-TFC membranes were qualitatively investigated using SEM (Hitachi SU 3500, Japan). For this purpose, a small piece of wet membrane was submerged in $\mathrm{LN}$ until it was completely flash-frozen. Then, it was immediately fractured manually to obtain clean cut. Membrane samples should be sputtered under vacuum with a thin layer of gold in Au sputtering system (Edwards, scancoat six) for producing electrical conductivity, elimination surface charging, and also minimization sample damage caused by the electron beam.

The captive bubble method (KSV Instruments CAM 101) is applied in order to measure the CA between water and membrane surface. The images were taken at room temperature using a digital 
camera (Imaging source model DMK 21F04). Three images of each samples were selected and then analyzed based on static measurement and Young/Laplace fitting methods. The equilibrium values were then steady state average of left and right angles.

MSD test was accomplished for evaluation of solvent (DI water) resistance behavior of the MMMs. For this purpose, several strips into a specific size $(2 \mathrm{~cm} \times 2 \mathrm{~cm})$ of the pre-weighed dry MMMs $\left(\mathrm{m}_{\mathrm{dry}}(\mathrm{g})\right)$ were dipped in DI water and shook well overnight. In each step, at the same time intervals (every $24 \mathrm{~h}$ ), three swollen samples were removed from the solution. After a quick surface wiping with filter papers, the samples were weighed again $\left(\mathrm{m}_{\text {wet }}(\mathrm{g})\right)$. The results were then analyzed and average of the measured swelling degree for each sample at special time interval was recorded. This process was continued until no further weight increase of the membrane was observed (equilibrium swelling or MSD $\left(m_{w e t}^{e q}\right)$ ). The MSD ( $\mathrm{mL}$ of sorbed DI water per gram of substrate $\left.\left(\mathrm{mL} \cdot \mathrm{g}^{-1}\right)\right)$ and equilibrium water uptake (EWU) of different substrates were calculated using the following equations [20,21]:

$M S D=\frac{\frac{m_{w e t}^{e q}-m_{d y}}{m_{d r y}}}{\rho_{w}}$

$\mathrm{EW} \mathrm{U}(\%)=\left(\frac{m_{w e t}^{e q}-m_{d r y}}{m_{w e t}^{e q}}\right) \times 100$

where $\rho_{w}$ is the DI water density $\left(\mathrm{g} \cdot \mathrm{mL}^{-1}\right)$ which was considered $0.997 \mathrm{~g} \cdot \mathrm{mL}^{-1}$ at room temperature. Basically, the overall porosity can be simply defined as weight of DI water trapped in $1 \mathrm{~m}^{3}$ of membrane structure. Accordingly, the overall porosity $(\varepsilon)$ of substrate membrane was calculated via gravimetric technique (as described in MSD test), as defined in the following equation [22]: 
$\varepsilon=\frac{m_{w e t}^{e q}-m_{d r y}}{A \times l \times \rho_{w}}$

where $A$ and $l$ are the area $\left(\mathrm{m}^{2}\right)$ and thickness (m) of the initial membrane samples, respectively. The thickness of the substrate layer was measured using Lorentzen and Wettre digital micrometer (L\&W instruments, with accuracy of $1 \mu \mathrm{m}$, Sweden). The thickness of each membrane sample was randomly measured at 5 different locations and the average of them were used in calculations.

A tensile strength tester measures the load applied as a function of elongation of the sample strips. Accordingly, mechanical strength properties were measured with a vertical universal tensile testing machine SANTAM (STM-20, Korea) equipped with a $6 \mathrm{~N}$ load cell at room temperature. The maximum tensile force of the test piece and its corresponding elongation are recorded. The tests were performed at a crosshead speed of $1 \mathrm{~mm} \cdot \mathrm{min}^{-1}$. The specimens were the rectangular strips of the membranes with dimensions of $70 \mathrm{~mm} \times 10 \mathrm{~mm}$. Three replicated membranes of each case were tested and the average values of tensile stress and elongation at break were reported.

The dynamic viscosity of casting solutions was measured using Modular Compact Rheometer (MCR 302, Anton-Paar) at the constant temperature of $20^{\circ} \mathrm{C}$.

\subsection{Experimental setup and protocol}

To assess the PWP of PSL and TFC membranes, a rectangular cross-flow laboratory-scale system was used to simultaneously test four membranes in parallel (Fig.1). The membrane effective area of each membrane module is $40 \mathrm{~cm}^{2}$. Cross-flow velocity was adjusted to $0.5-0.7 \mathrm{~m} . \mathrm{s}^{-1}$ during flushing, pressurizing and permeability. To eliminate the influence of membrane compaction during the determination of the PWP, all PSL and RO TFC membranes were subjected to pressurization for 30 minutes with pure water at the desired applied pressure of 4 bar and 15 bar, 
respectively. The operating temperature was controlled in line (retentate stream) at $25 \pm 1{ }^{\circ} \mathrm{C}$ by using a refrigerated circulating water bath. Measurements continued at the above mentioned pressure until an approximately steady state flux was observed. Finally, PWP was recorded for $\operatorname{PSL}\left(J_{w}^{P S L}\right)$ and TFC ( $\left.J_{w}^{T F C}\right)$ membranes using the following equation:

$$
J_{w}=\frac{Q_{w}}{A_{m}}
$$

where $Q_{w}\left(\mathrm{~L} \cdot \mathrm{h}^{-1}\right)$ is the permeate flow of pure water and $A_{m}\left(\mathrm{~m}^{2}\right)$ is the effective membrane area. Based on the PWP values and overall porosity data, mean pore radius $\left(\mathrm{r}_{\mathrm{m}}(\mathrm{nm})\right)$ of membrane substrate was calculated via Guerout-Elford-Ferry equation (Eq. (5)) [22].

$$
r_{m}=\sqrt{\frac{(2.9-1.75 \varepsilon) \times 8 \mu \times l \times Q_{w}}{\varepsilon \times A \times \Delta P}}
$$

where $\mu$ is the water viscosity $\left(8.9 \times 10^{-4} \mathrm{~Pa} . \mathrm{s}\right)$ and $\Delta \mathrm{P}$ is the operation pressure ( 4 bar).

TFC membrane performance (ASPF and ASRE) was evaluated under brackish water testing conditions (15 bar, $\sim 3.85-3.95 \mathrm{mS} / \mathrm{cm}$ of $\mathrm{NaCl}$ aqueous feed solution at $25 \pm 1{ }^{\circ} \mathrm{C}$, solution $\mathrm{pH}$ of $\sim 6$ and total recycle mode). All permeate flux and salt rejection were measured for $6 \mathrm{~h}$. During this period, the permeate samples were collected continuously and gravimetrically. The cumulative weights are converted to cumulative volumes and from the slope of the cumulative volume versus operating time curve, the permeate flux, $J_{p}\left(\mathrm{~L}_{\mathrm{m}} \mathrm{m}^{-2} \cdot \mathrm{h}^{-1}(\mathrm{LMH})\right)$, was calculated using the following equation:

$$
J_{p}=\frac{1}{A_{m}} \frac{d V}{d t}
$$

where $V(\mathrm{~L})$ is the volumetric flow rate of permeate and $t(\mathrm{~h})$ is the sampling time. 
ASRE was calculated by measuring the electric conductivity of feed $\left(E C_{f}\right)$ and permeate $\left(E C_{p}\right)$ solutions using an electrical conductivity meter (Labor-Konduktometer 703, Knick Co.) as follow:

$$
\operatorname{ASRE}_{a p p}(\%)=\left(1-\frac{E C_{p}}{E C_{f}}\right) \times 100
$$

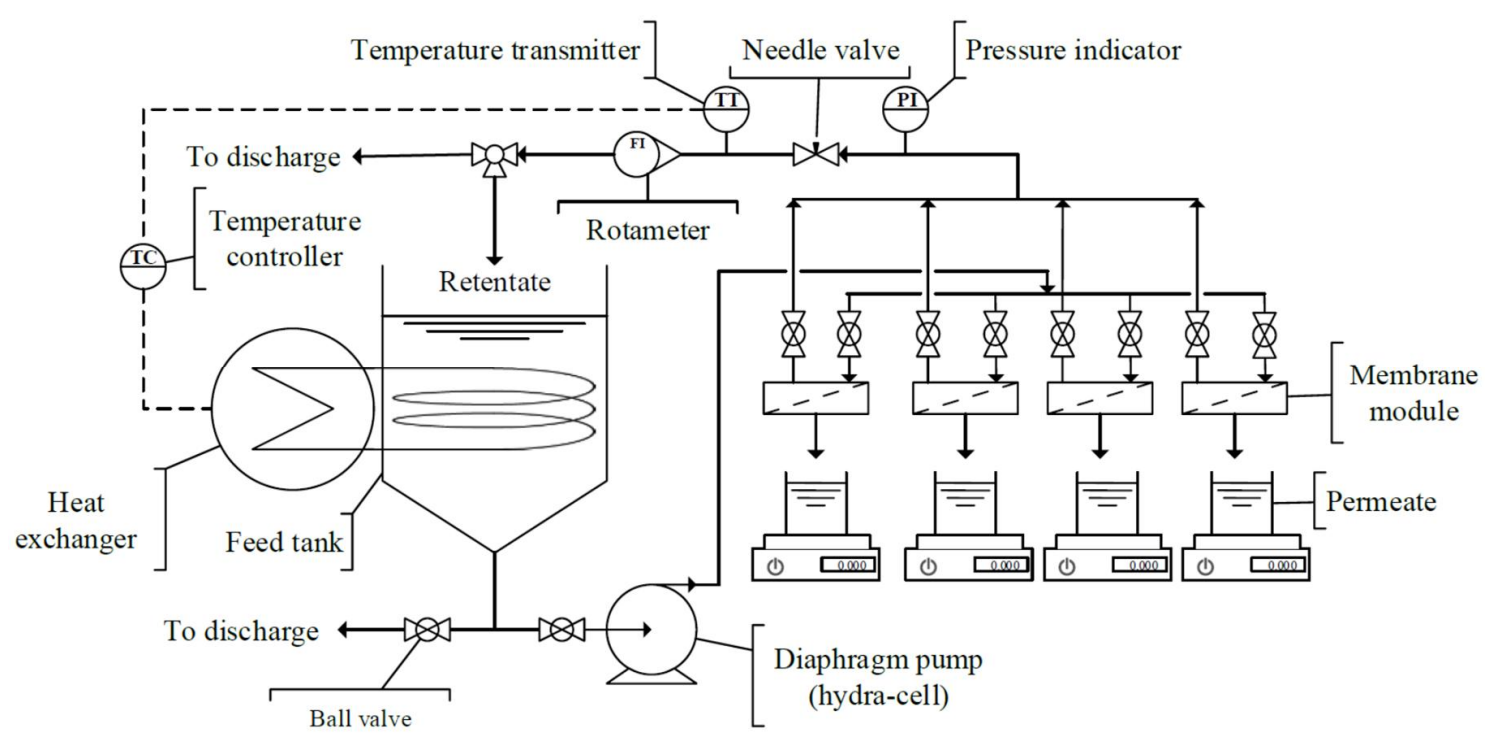

Fig. 1. Schematic diagram of cross-flow laboratory-scale system.

\section{Results and discussion}

\subsection{ATR-FTIR analysis}

IR spectra of PSLs and PA-TFC membranes with various WSD loading are shown in Fig. 2. The main characteristic peaks at 1585,1504 and $1488 \mathrm{~cm}^{-1}$ are attributed to aromatic in-plane ring bend stretching vibration $\left(\mathrm{CH}_{3}-\mathrm{C}-\mathrm{CH}_{3}\right.$ stretching), the peak at $1408 \mathrm{~cm}^{-1}$ is due to $\mathrm{C}=\mathrm{C}$ aromatic ring stretching, two weak peaks at 1387 and $1365 \mathrm{~cm}^{-1}$ are associated with $\mathrm{C}-\mathrm{H}$ symmetric deformation vibration of $\mathrm{C}\left(\mathrm{CH}_{3}\right)_{2}$, the peaks at 1325 and $1295 \mathrm{~cm}^{-1}$ are assignable to the asymmetric $\mathrm{O}=\mathrm{S}=\mathrm{O}$ stretching vibration, the prominent peak at $1242 \mathrm{~cm}^{-1}$ is corresponded to asymmetric $\mathrm{C}-\mathrm{O}-\mathrm{C}$ stretching (vibration of aryl-O-aryl group), the peaks at 1169 and $1151 \mathrm{~cm}^{-1}$ are assigned to 
symmetric $\mathrm{O}=\mathrm{S}=\mathrm{O}$ stretching vibration, and the peak at $833 \mathrm{~cm}^{-1}$ is related to hydrogen deformation of para-substituted phenyl groups in-phase out-of-plane. Finally, peaks between $\sim 2900$ and $\sim 3100 \mathrm{~cm}^{-1}$ related to aromatic and aliphatic C-H stretching vibrations [23-27]. Moreover, all peaks of PSf in MMMs, with less intensity because of WSD in substrate, are also visible in the IR spectra over a wavenumber range of $1800-800 \mathrm{~cm}^{-1}$.

In the case of TFC membrane, since the thickness of polyamide skin layer is thin ( 200 nm), the FTIR analysis of this layer was problematic. In addition, the penetration depth of IR radiation is greater than $300 \mathrm{~nm}$, at wavenumbers lower than $2000 \mathrm{~cm}^{-1}$. As a consequence, the spectra reveal not only bands assignable to the PA, but also those of PSf substrate layer, as the IR beam penetration depth exceeds and anyway all the way through the PA layer. Nevertheless, the FTIR spectra reveals that the specific functional groups of PA can be detected over all TFC membranes. The IR spectrum of TFC membrane demonstrates four characteristic peaks at $1660 \mathrm{~cm}^{-1}, 1605 \mathrm{~cm}^{-}$ ${ }^{1}, 1541 \mathrm{~cm}^{-1}$ and $1449 \mathrm{~cm}^{-1}$ which are mainly respected to primary amide band $(\mathrm{C}=\mathrm{O}$ stretching vibration of amide, $\mathrm{C}-\mathrm{N}$ stretching and $\mathrm{C}-\mathrm{C}-\mathrm{N}$ deformation vibration in a secondary amide group), aromatic ring $(\mathrm{C}=\mathrm{C}$ ring stretching vibration and $\mathrm{N}-\mathrm{H}$ stretching of amide), secondary amide band (in-plane $\mathrm{N}-\mathrm{H}$ bending motion and $\mathrm{C}-\mathrm{N}$ stretching vibrations of $-\mathrm{CO}-\mathrm{NH}$ group), and carboxylic group $(\mathrm{C}=\mathrm{O}$ stretching and $\mathrm{O}-\mathrm{H}$ bending of carboxylic acid $)$, respectively. Other peaks are observed between 900 and $1200 \mathrm{~cm}^{-1}$ which are assigned to skeletal aliphatic $\mathrm{C}-\mathrm{C} /$ aromatic hydrogen bending and aliphatic $\mathrm{C}-\mathrm{H}$ rocking of PA [23, 28-32]. In addition, the peak at $1387 \mathrm{~cm}^{-}$ ${ }^{1}$ is attributed to the mixture of $\mathrm{C}-\mathrm{N}$ stretching and in-plane $\mathrm{N}-\mathrm{H}$ deformation tertiary amide. In the presence of WSD in PSL, the peaks of TFC membranes have shifted, reduced or promoted slightly compared to corresponding TFC membrane. These relationships may partly be explained by less and more PA formation stemming from the presence of WSD on the surface of the PSLs. 
Typically, natural wood has a characteristic broad peak at $3359 \mathrm{~cm}^{-1}$ dominated by the stretching vibrations of the $\mathrm{OH}$ groups in cellulose, hemicelluloses, lignin and maybe absorbed water. The bands around 2881-2928 $\mathrm{cm}^{-1}$ are attributed to the $\mathrm{C}-\mathrm{H}$ stretching and bending in $\mathrm{CH}_{3}$ (methyl and methylene groups). The peaks at $1737 \mathrm{~cm}^{-1}$ and $1594 \mathrm{~cm}^{-1}$ were corresponded to the $\mathrm{C}=\mathrm{O}$ stretching vibration in the hemicellulose and the aromatic stretching vibration of lignin, respectively. Furthermore, the observed peak at $1241 \mathrm{~cm}^{-1}$ represented the presence of hemicellulose in WSD. The open sever pick observed in the range of 1000-1200 indicated the C$\mathrm{O}$ band stretching of the $\mathrm{C}-\mathrm{O}-\mathrm{H}$ and $\mathrm{C}-\mathrm{O}-\mathrm{C}$ groups in the anhydroglucose ring, hemicelluloses and lignin. Similar results can be found in other literatures [33-35] which is consistent with our study. In the case of MMMs, no additional broad band is observed at least at low WSD concentration. Also, there is no effective chemical bond between sawdust particles and polymer chains. As WSD amount increases, only the intensity of $\mathrm{OH}$ band a little bit increases, especially for PSL-14/05 and a new band is observed at $3352 \mathrm{~cm}^{-1}$ which is only related to WSD particles. This is due to the fact that at low WSD loading (up to $1 \mathrm{wt} . \%$ ), most of the WSD particles are settled down in membrane substrate polymer solution and there are almost no considerable particles near the membrane surface which can be detected by IR beam. By increasing WSD concentration (5 wt.\%), although the extent of interaction between the WSD particles and polymer chain reduces due to the particle agglomeration and the rate of sedimentation increases, the number of particles near or on the membrane surface increases and at this conditions, the IR beam penetration depth can be detected some of WSD particles. This phenomenon caused that the surface structure of PSf substrate should be altered via increasing WSD loading. 

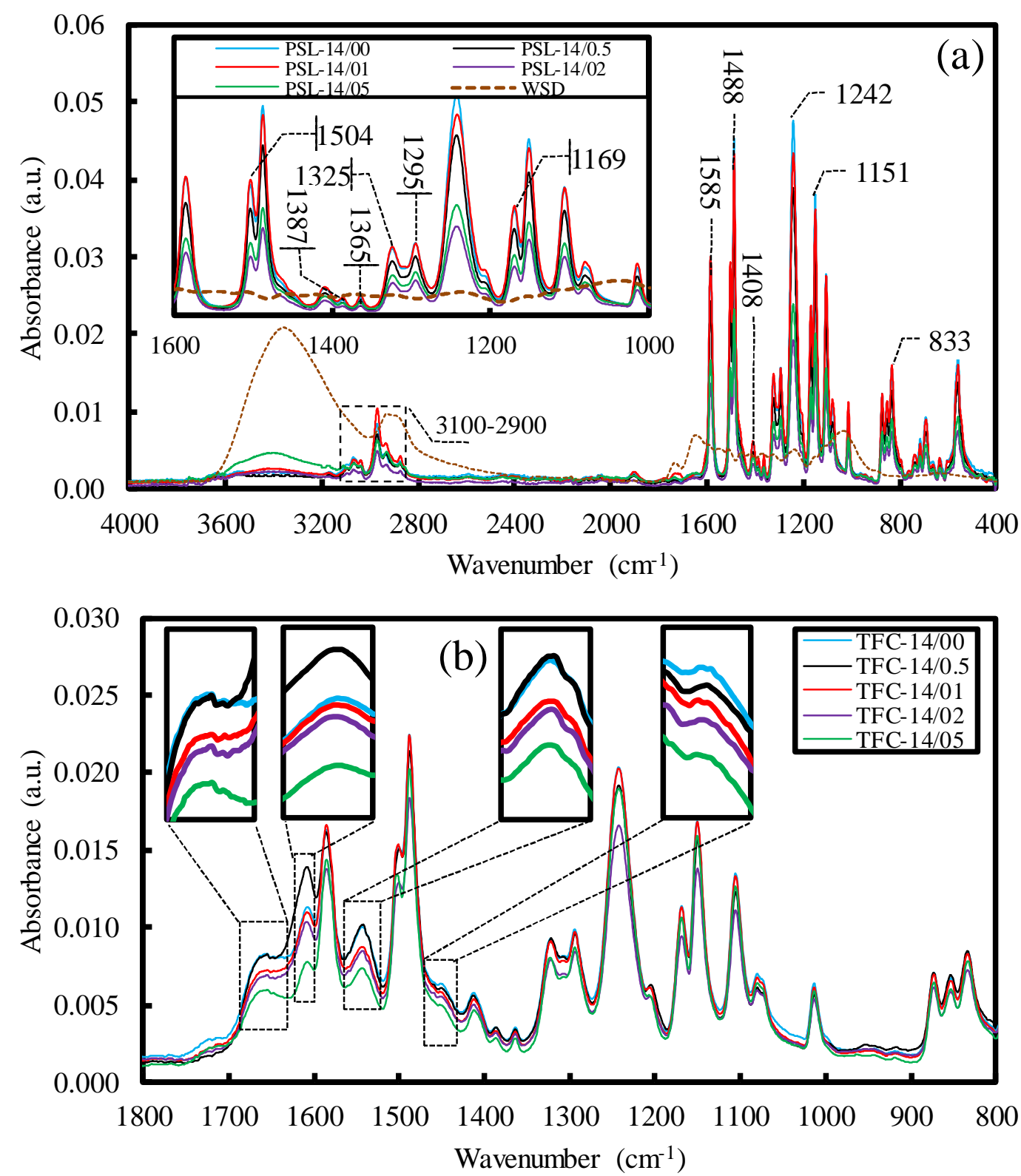

Fig. 2. IR spectra of membrane samples with various loading of WSD (a) WSD and PSLs and (b) TFC membranes.

\subsection{PSD analysis}

Grinded sawdust PSD was employed to determine the effectiveness of ball milling process as a function of grinding time. Fig. 3 indicates the particle size classes based on differential volume density, differential number density, cumulative volume density and cumulative number density. 

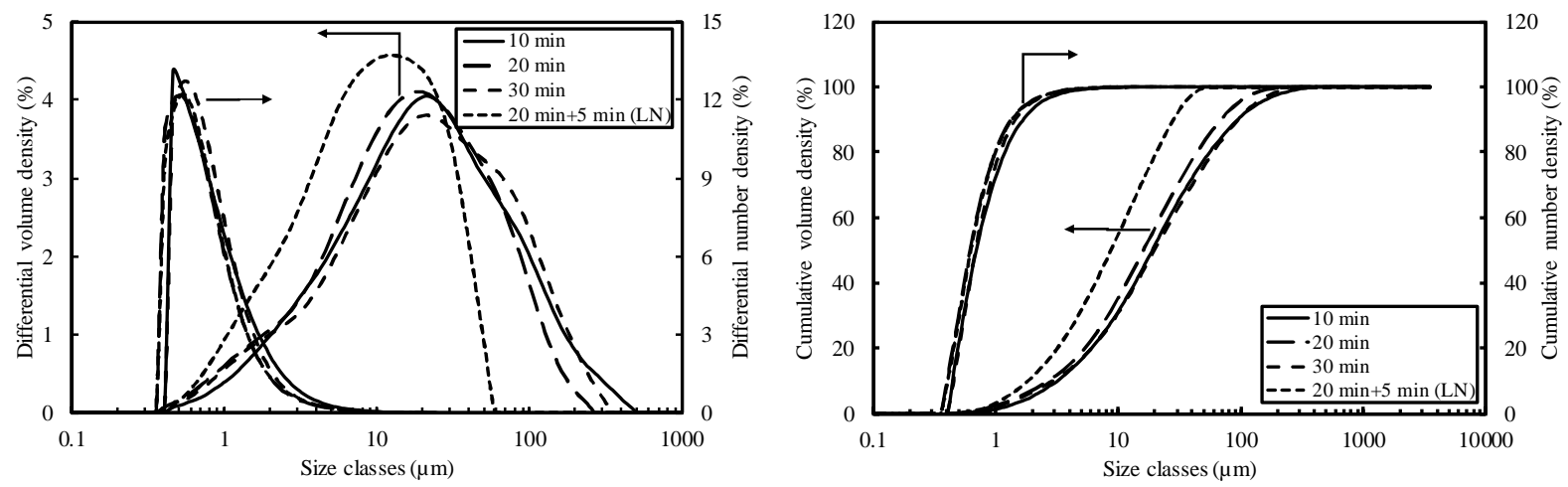

Fig. 3. Effect of grinding time and LN on volume density, number density, cumulative volume and cumulative number of sawdust particles.

As shown in this figure, the sawdust particle size classes are between $\sim 300 \mathrm{~nm}$ to $400 \mu \mathrm{m}$. After 10 minutes dry grinding, with respect to differential and cumulative number density, more than $99 \%$ of sawdust particles are in the classes below $5 \mu \mathrm{m}$. In fact, most of the particles are in the size classes between $300 \mathrm{~nm}$ to $5 \mu \mathrm{m}$. Nevertheless, the authors tried to reduce the particle volume density by increasing grinding time and using LN. In this process, the sawdust particles, after 20 minutes dry grinding, were directly contacted with LN. After the LN was evaporated, the sawdust particles were grinded again for 5 minutes.

Data presented in Fig. 3 also reveal that increasing the grinding time alone has little effect on volume and number density. While the use of LN has clearly changed the biggest particle size classes from $400 \mu \mathrm{m}$ to $60 \mu \mathrm{m}$. Consequently, using $\mathrm{LN}$ has a great impact, especially on volume density of particles. This sample was used in membrane preparation.

According to our methodology in grinding process, most of the sawdust particles $(\sim 80 \%)$ based on differential and cumulative number density are below $1 \mu \mathrm{m}$. Also, at this condition more than 99\% number of sawdust particles are below than $4 \mu \mathrm{m}$. Since the thickness of PSf substrate layer is usually around $50-70 \mu \mathrm{m}$ (membrane casting thickness was $200 \mu \mathrm{m}$ ), the sawdust particles 
expected to be dispersed within the polymer network. It was observed during experiments, most of large particles are sedimented from polymer solution because of gravity force during the degassing process of casting solutions.

\subsection{SEM analysis}

According to apparent morphology of the WSD presented in Fig. 4, the unclean surface of WSD (Fig. 4a) which is common with raw natural WSD, is covered by hemicellulose, lignin, and extractive compounds such as wax substances, pectins, and natural oils. Oppositely, the surface of relatively cleaned WSD (washed with acid and base, Fig. 4b) looks cleaner and smoother [36].

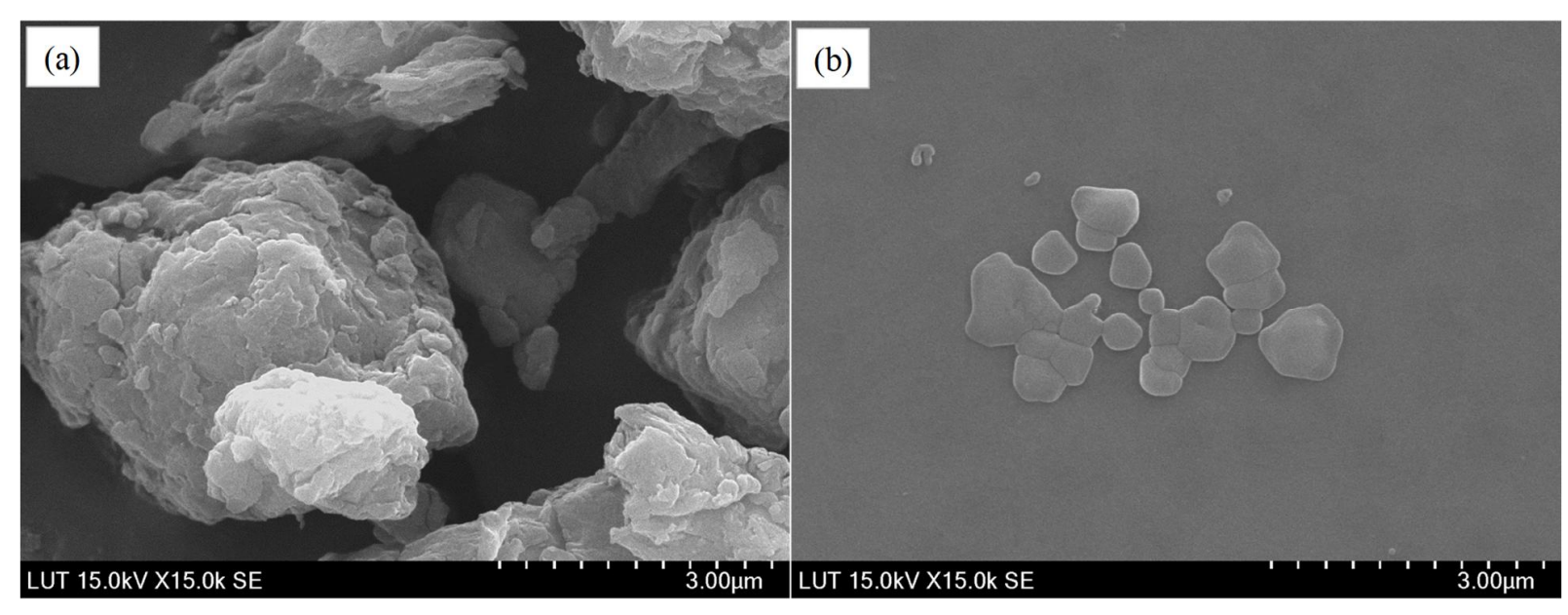

Fig. 4. SEM images of the (a) unclean and (b) partially cleaned raw WSD.

Among the all prepared substrates, PSL-14 with various loading of sawdust were selected as substrate to investigate the structural and physicochemical characteristics because of relatively proper separation performance. Accordingly, the cross-section morphology of these selected mixed matrix substrates was illustrated by SEM micrographs in Fig. 5. As can be observed, all the substrates have a typical asymmetric structure consisting of an approximately top dense skin layer, a porous sub-layer and finger-like pores along with several macrovoids or cavities at the bottom. This structure is related to the strong affinity and miscibility between polymer solvent (NMP) and 
non-solvent (DI water) in coagulation bath [37]. Furthermore, it is noteworthy that sawdust is a lingo-cellulosic materials consisting of cellulose, hemicellulose and lignin [35]. Since these materials contain various functional groups (according to FTIR result), presence of them in polymer casting solution have significant effects on the substrate membrane morphology. Firstly, according to images with the highest magnification, by increasing sawdust loading, the number of finger-like structure and length of them are increased and decreased, respectively. This result is likely to be related to the instantaneous demixing between DI water and NMP in coagulation bath and casting solution, respectively.

Rate of demixing has a direct relationship with the thermodynamic instability and the interaction diffusivities (kinetic behavior) between components in the system during precipitation of the casting solution. As a result, sawdust causes the polymer solution to be less stable and instantaneous demixing of casting solution would occur during immersion precipitation process [20, 38]. Secondly, sawdust particles lead to suppression of macrovoids and decreasing the membrane thickness (see Figs. 5 and 8) because of increasing viscosity of the casting solution. Viscosity values of casting solution increase according to PSL-14/00 (0.269 Pa.s $)<$ PSL-14/0.5 (0.298 Pa.s) < PSL-14/01 (0.306 Pa.s) < PSL-14/02 (0.312 Pa.s) < PSL-14/05 (0.316 Pa.s). Indeed, the diffusional exchange rate between solvent (NMP) and non-solvent (water) during the precipitation process in coagulation bath have been slowed down (promotes delayed demixing) by increased viscosity [20]. Thirdly, at high loading of sawdust (> 2 wt.\%), particle agglomeration occurred and probably diminished macrovoid formation in the sublayer. The last reason is that there is no effective chemical bond between sawdust particles and polymer chains, which has already confirmed by FTIR results. In other words, WSD creates an exfoliated and intercalated mixed matrix structure, which reduces the interaction among the polymer chains. 


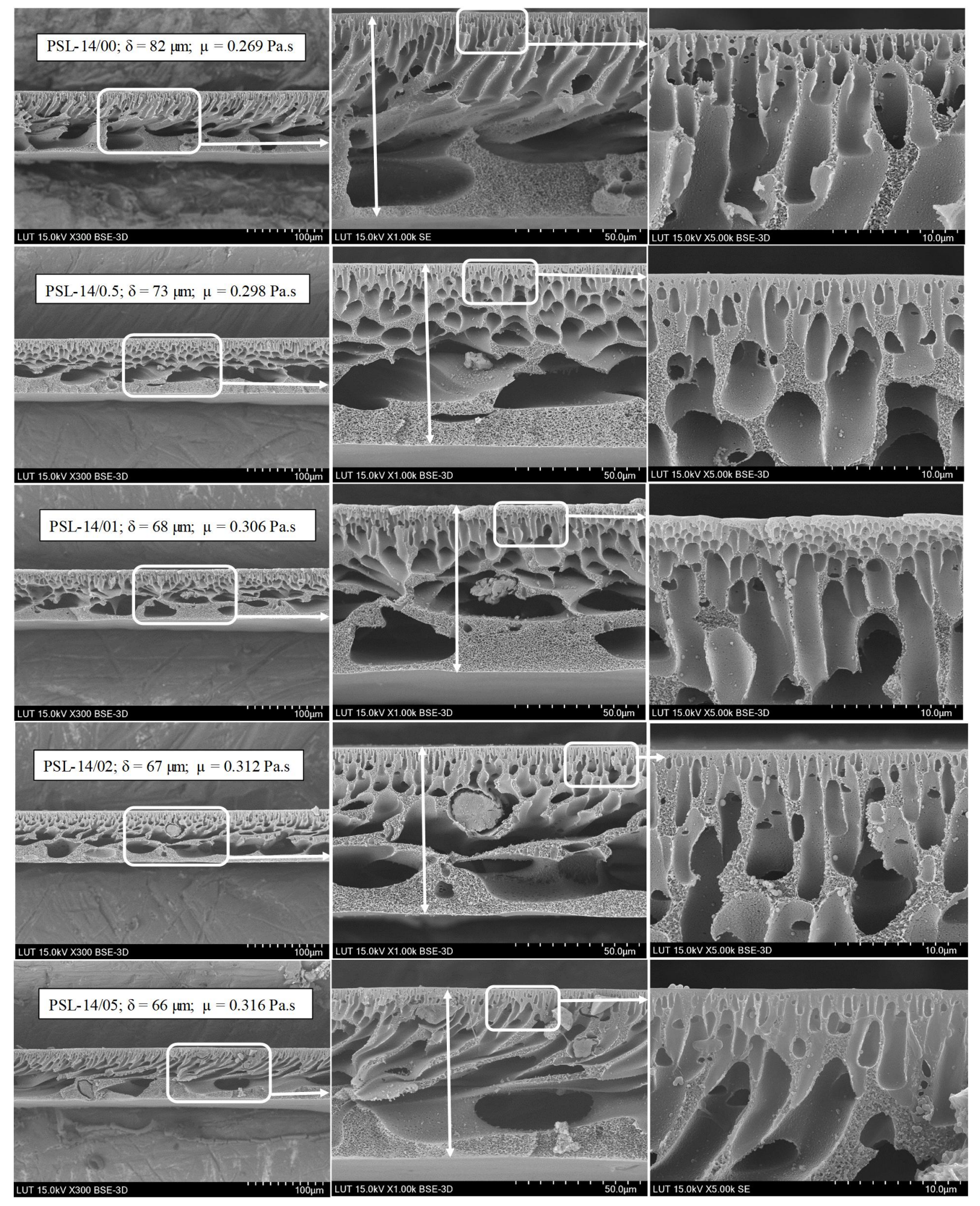

Fig. 5. SEM cross-section images of PSL-14 MMMs with different loading of sawdust. 
All in all, the number of macrovoids and final structure is highly dependent on the superiority of instantaneous or delayed demixing, comes from the polymer concentration, WSD loading and degree of WSD agglomeration in the polymer casting solution and substrate.

The top surface of three PSf substrates (PSL-14/00, PSL-14/01, and PSL-14/02) and cross-section morphology of their corresponding TFC RO membranes (TFC-14/00, TFC-14/01, and TFC-14/02) are evaluated by SEM and presented in Fig. 6 (a) and (b), respectively.

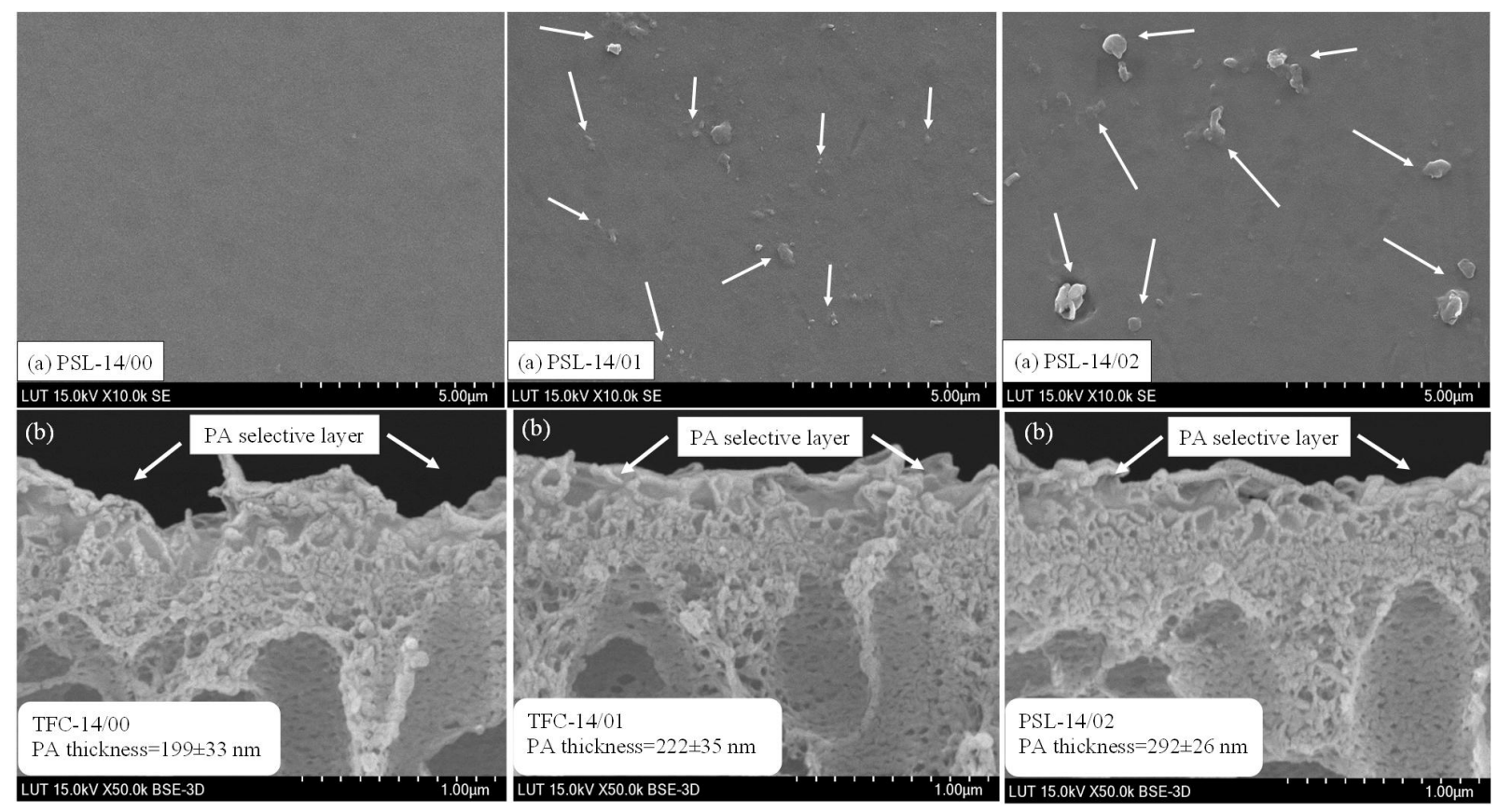

Fig. 6. SEM images of (a) the top surface of three different substrates with various loading of sawdust $0 \%, 1 \%$, and $2 \%$ and (b) the PA cross-section morphology of them.

Top surface SEM images (Fig. 6a) of PSLs (PSL-14/00 compared to PSL-14/01 or PSL-14/02), clearly shows the sawdust particles on the upper surface of MMMs. With respect to Fig. 6 (a), as the sawdust particle concentration reaches to around $2 \mathrm{wt} . \%$, the aggregation occurs. Obviously, it can be seen that morphology and particles distribution of PSLs are varied by WSD loading increment. Furthermore, the sawdust particles seem not to be well covered by the polymer matrix 
and very small void is found in the interface of polymer and sawdust, particularly at higher filler loadings. These results have already been confirmed by FTIR analysis. At low concentration of WSD, no additional peak is observed in FTIR and it seems that most of the sawdust particles are placed in layers below the membrane top layer. On the other hand, by increasing the concentration of WSD which is not only increasing the intensity of the sawdust agglomeration, but also their number increases on the surface of the substrate layer. Thus, an additional wide peak can be seen at high loading of WSD in the range of $3300-3400 \mathrm{~cm}^{-1}$ because of hydroxyl group in WSD particles (Fig. 2).

The PA layer images (Figs. 6 (b)) are not only confirming the formation of thin PA film on the surface of substrates, but also indicate that the thickness of the film was approximately in the range of 200-300 nm. Remarkably, thin film thickness is visually measured from the apparent top of the substrates using the drawing tool in Image $\mathbf{J}$ software; hence, PA layer formed inside substrate pores is not considered. As can be observed, no significant increment in the thickness of PA layer was found at low loading of WSD in the substrate compared with pure substrate. Interestingly, the thickness of PA layer was observed to increase significantly by increasing WSD loading to $2 \mathrm{wt}$.\%. A strong relationship between PA layer characteristics (thickness and structure) and substrate properties (surface roughness, pore size, hydrophilicity, the presence or absence of any additive, and type of additive) has been reported in the literatures. For example, Misdan et al. [1] observed that the thickness of PA layer increased by increasing PSf concentration in the substrate. They believed that smaller pores would limit the diffusion of aqueous solution deep into the pores, developing thicker PA layer. On the other hand, Ghosh and Hoek [3] reported that the presence of hydrophilic materials in the PSf substrates enhanced the penetration of aqueous solution into the pores, developing thinner PA layer. It is likely the diffusion rate of MPD from inside pore to 
membrane surface would be certainly affected by the presence of sawdust. There is a possibility that the MPD inside pore can interact with sawdust through hydrogen bonding. The interaction between these two phenomena determines the final PA thickness. The concentration of WSD on the surface of the membrane increased with the successive increase of WSD loading (Figs 6 (a)). Increase in WSD loading decreased the pore diameter of the substrate because increase in the viscosity of casting solution. In such circumstance, the PA layer thickness increased gradually.

Fig. 7 displays the PA surface view of the TFC membranes prepared by identical IP on various MMMs. Generally, PA TFC membrane is rough, having uniform "ridge-and-valley" structure. This observed surface morphology is characteristic of MPD/TMC [26]. In this regard, the variation in surface morphology of TFC membranes compared to the MMMs (Fig. 6) confirmed that PA active layer was successfully formed over substrates, which have previously confirmed by FTIR and cross-section PA SEM results. In these images, the white and dark parts corresponded to the peaks and valleys, respectively. Although the surface of TFC-14/00 and TFC-14/0.5 membranes have completely "ridge-and-valley" structure, PA layer of TFC-14/01, TFC-14/02, and TFC-14/05 have a little bit different structure and exhibit more "leaf-like" folds along with "ridge-and-valley" structure on their surface. In other words, further increases in the solid content such as WSD or PSf of substrate altered the PA structure by covering the valley of PA film, as evidence clearly in TFC-14/05. It is predicted that the leaf-like structure of PA surface gradually converted to nodular type, particularly at high concentration of PSf ( 16 wt.\%) and WSD ( $\geq 2 \mathrm{wt} . \%)$ [1]. As mentioned above, two different morphology of PA top surface is mainly related substrate physicochemical properties such as hydrophilicity, surface roughness, porosity, and pore size. Furthermore, the absence or presence of nanoparticles and their concentration on the surface of substrates is one of the main factors that affect the PA structure. As explained by Namvar et al. [20], the diffusion rate 
reduction of monomers during IP is one of the reasons for the changing the structure of PA layer. By increasing the concentration of sawdust in the polymer matrix more amounts of its particles are available on top surface of PSL-14/02 substrate membrane. Sawdust nanoparticles act as an impediment during MPD diffusion through support. Therefore, the rate of MPD transport into surface pores considerably decreases and changes PA structure after immersing in TMC solution.
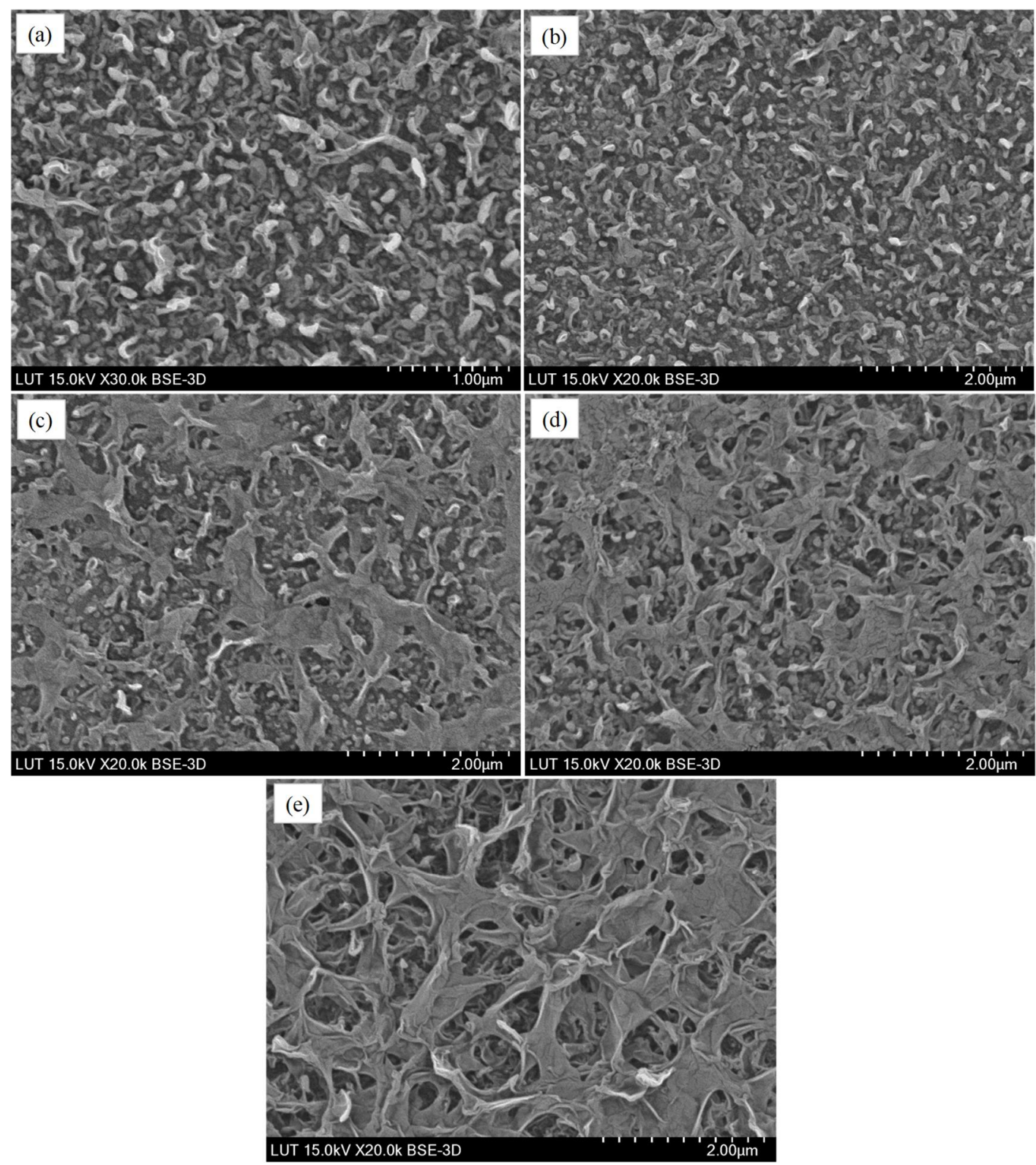
Fig. 7. Top surface image of PA layer polymerized on MMMs with different loading of sawdust (a) TFC-14/00, (b) TFC-14/0.5, (c) TFC-14/01, (d) TFC-14/02, and (e) TFC-14/05.

\subsection{MSD, EWU, overall porosity, mean pore radius and thickness of various PSLs}

Fig. 8 provides the experimental data of MSD, EWU, overall porosity, mean pore radius, and thickness of membranes with different polymer concentration and sawdust loading in the substrate. Following the addition of WSD, the overall porosity is gradually increased. Indeed, the presence of WSD in the casting solution affects the phase inversion process and subsequently the final membrane structure as shown previously in Fig. 5. Also, membrane porosity is strongly related to the thermodynamic and precipitation kinetic parameters of membrane formation [39].

In this study, the thermodynamic instability of the polymer solution outweighs the kinetic hindrance when the WSD adding amount is low ( $\leq 2 \mathrm{wt} . \%)$. Thus, a cross-section structure with more macrovoids and cavities was formed. Furthermore, as stated earlier, no effective chemical bond has taken place between sawdust particles and polymer chains, which reduces the interaction among the polymer chains and increases the overall porosity.

Closer inspection of the figure shows the overall porosity gradually decreased with further increase in WSD (>2 wt.\%). The observed decrease could be directly because the intensity of WSD particle agglomeration increased at high WSD loading (PSL-14/05 in Fig. 5). Another possible explanation for this is that the thermodynamic enhancement is overtaken by the kinetic hindrance because of the viscosity increasing when WSD is increased further [39]. This is resulted in formation of sponge type structure at least at the bottom of the sublayer.

In the case of polymer concentration, the graph illustrates that there has been a slight decline in overall porosity by increasing polymer concentration from 12 to $16 \mathrm{wt} . \%$. This can be attributed 
to increasing of casting solution viscosity with increasing of polymer concentration. Increasing the polymer solution viscosity tends to reduce penetration rates, thereby producing a slower demixing in the phase inversion process. Consequently, shorter and narrower macrovoids along with thick walls and sponge-like structure in the substrate stemming from delayed phase inversion $[2,5]$.

It is expected that MSD and EWU increase by increasing the concentration of polymer. Because, the amount of solid in the substrate as well as the membrane thickness increased by increasing the polymer concentration. Contrary to expectations, the swelling degree (i.e. MSD) of pure substrates increased by decreasing polymer concentration. A possible explanation is hydrophobicity of PSf and thus appears with less degree of swelling even at high concentration. Another possible explanation is that the porosity of substrate increased by decreasing polymer concentration. In other words, solvent diffusion coefficient was lower at higher polymer concentration because of lower chain mobility and reduction in pore size [40]. Consequently, the possible interference of porosity cannot be ruled out. Furthermore, the swelling degrees of all pure PSf membranes are lower than MMMs. As stated before, incorporation of WSD causes more flexible polymer chains and the distance between chains changed due to the lack of strong bond and cross-linking. Hence, the addition of WSD increased the swelling property of the substrate when compared with pure PSf. As shown in Fig. 8, both MSD and EWU of as-prepared substrates increased first and then decreased with following increase of sawdust loading. These observations may partly be explained by the fact that with successive increase in additive loading, repulsive force between polymer segments along with leachability of the additive enhances and this leads to formation of macrovoids and cavities due to incidence of more number of larger pores and macrovoids, respectively [21]. Similar behavior can be observed in the case of MSD and EWU at high loading of WSD. Therefore, the identical interpretation is directed to loading of WSD on MSD and EWU of substrates which has already been 
discussed. Also, it should be noted that at high sawdust loading, due to agglomeration and larger particle size, the specific surface area and subsequently contact sites (interface) between filler and water molecule have been reduced. Thus, the pores on the surface and micropores, mezopores, macropores as well as cavities inside the substrates are responsible for accommodating water in the membranes [2].

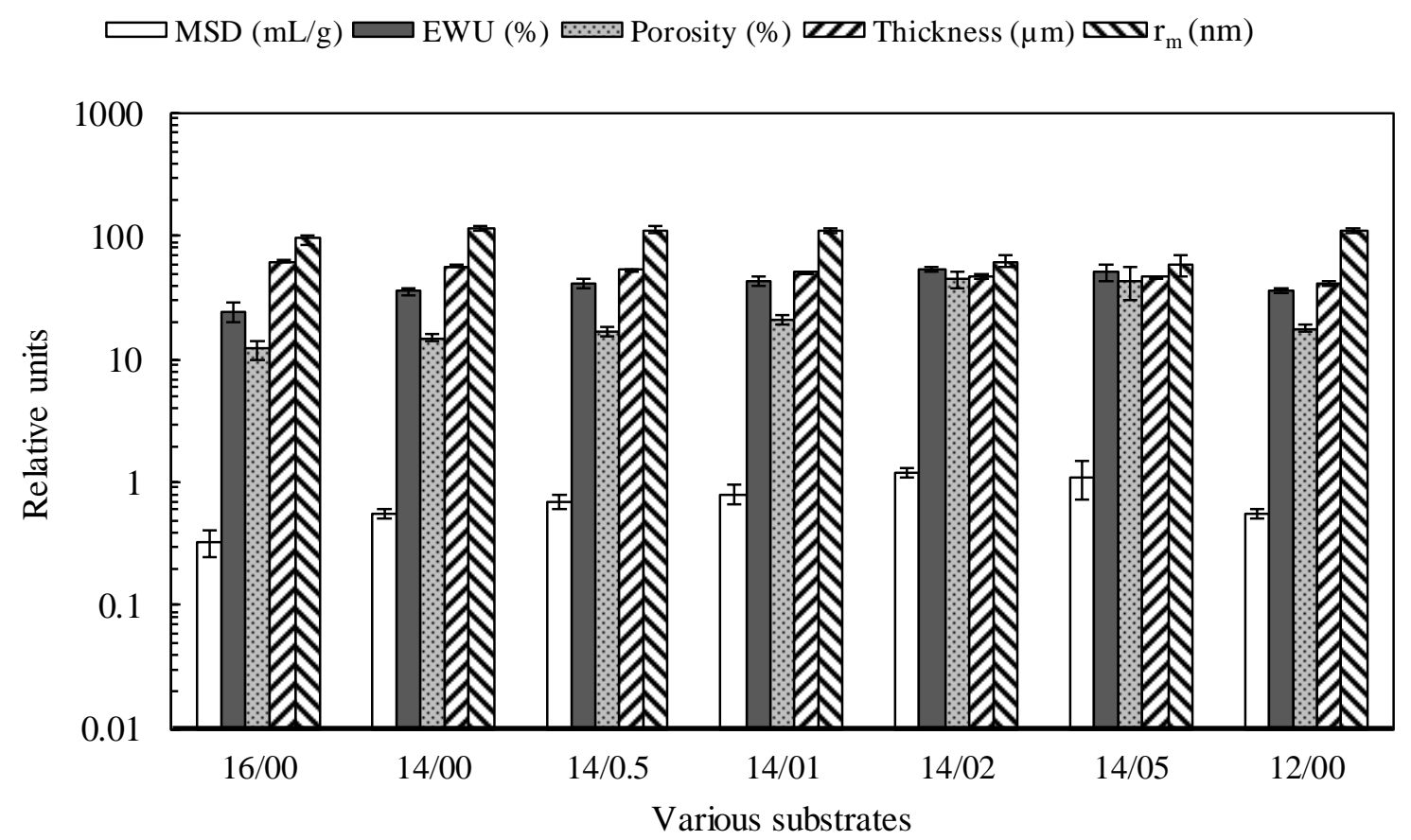

Fig. 8. Experimentally determined values of MSD, EWU, porosity, thickness, and mean pore radius of various substrates.

\subsection{Hydrophilicity analysis}

The apparent contact angle values of different substrates and PA-TFC membranes, as shown in Fig. 9, indicate a correlation between increase in concentration of WSD and hydrophilicity of substrate and PA-TFC membranes. The contact angles of substrates remained approximately constant as WSD concentration raised from 0 to $1 \mathrm{wt} . \%$. However, incorporation of WSD in concentration above $1 \mathrm{wt} . \%$ results in increasing the contact angle. As a matter of fact, two contrast 
phenomena affect change in the contact angle values of substrate and TFC membranes. On the one hand, WSD entangled in the polymer matrix give rise to more hydrophilic character. On the other hand, the surface roughness of the substrate, particularly at high loading of WSD, amplifies the hydrophobicity which can lead to increase of contact angle of substrates.

Totally, the results of our study show a small range of variability in measured contact angle and hydrophilicity up to $1 \mathrm{wt} \%$ of WSD. While, for concentration above $1 \mathrm{wt} . \%$ the hydrophobicity starts to increase as values of contact angle.

Fig. 9 shows that there is a slight rise in the case of contact angle values of PA layer by increasing in PSf concentrations. This is relatively attributed to the pore size and surface porosity of substrate were obviously altered (Fig. 5) with increasing PSf concentrations in which higher concentrations tended to produce smaller pores and lower surface porosity. Tight pore structure of the substrate formed "leaf-like" and in the following "nodular" structures which resulted in quantitatively rougher surface morphology and a slight increase observed in contact angle values [1].

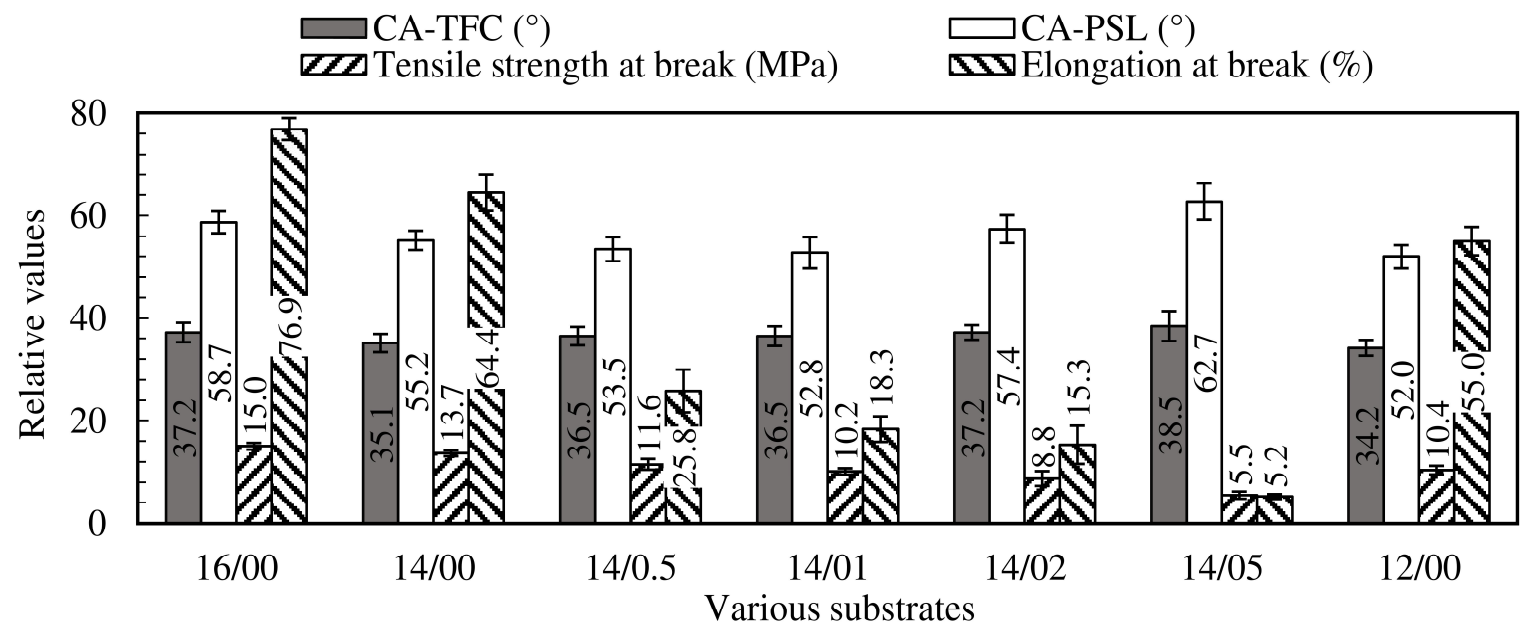

Fig. 9. Experimentally determined values of contact angle and mechanical properties of various substrates. 


\subsection{Mechanical analysis}

The mechanical characteristics of the synthesized MMMs depend on several factors including the concentration of polymer solution, loading of additive into polymer casting solution, particle size, particle agglomeration (dispersion intensity), and the affinity of adhesion/contact in the interface of polymers and additives [41]. Usually the incorporation of additives, particularly nanoparticles, into the polymer casting solution alters the microstructure, overall porosity, components transport, and mechanical properties of the membranes $[16,42]$. Accordingly, the impact of sawdust loading on the mechanical properties including tensile stress and elongation at break of some selected substrates prepared at different loading of WSD and polymer concentration are plotted in Fig. 9. As expected, the ultimate tensile strength (MPa) and elongation at break (\%) of MMMs are reduced with an increase and a decrease in WSD loading and polymer concentration, respectively. In the case of polymer concentration, it is obvious that PSf is a mechanically strength polymer and pure PSf membranes show acceptable mechanical properties. The observed decrease in mechanical properties could be attributed to the fact that decreasing the polymer concentration altered the membrane morphology (pore size, pore shape, overall porosity, and thickness) from almost sponge-type to more finger-like, which can reduce the substrate mechanical properties. In other words, the finger like macrovoids were suppressed with increasing PSf concentration and the structure became much denser [2].

Considering the obtained data for MMMs, both tensile strength and elongation at break of pure PSf substrate decreased by the addition of WSD into polymer matrix. There are three possible explanations for these results. First of all, with respect to the SEM cross-section images (Fig. 5), the incorporation of sawdust resulted in formation of macropores within the sublayer, and hence the increase of overall porosity weakened the strength of the membrane [42]. Secondly, WSD has 
conducted in a reduction of plasticity and flexibility of the polymer chains, so the movement of polymer chains has been restricted and MMMs will become more rigid. In this regard, as described by Vilakati et al. [16], the polymer toughness is promoted because of poorly interaction between this kind of additives and some polymers. The last but not the least, there is no effective chemical bond between sawdust particles and polymer chains as confirmed by FTIR results. Thus, the applied load was hardly transferred from polymer to fillers. As a matter of fact, lack of significant interfacial action between polymer chain and WSD nanoparticles is the major factor that affect mechanical strength of as-prepared substrates.

The high amount of sawdust particles $(\sim 5 \mathrm{wt} . \%)$ has clearly influenced the mechanical properties of membranes due to the non-uniform distribution in polymer casting solution and agglomeration throughout the PSf matrix. These behaviors are consistent with Sabeti Dehkordi et al. [43] findings, saying that the tensile strength at break decreased from 5.62 to $4.91 \mathrm{MPa}$ with increasing organically modified mont-morillonite (OMMt) loading from 0.5 to $5 \mathrm{wt} . \%$ in polymer solution. Eventually, although the mechanical properties of MMMs are weaker than pure PSf, non-woven PET is strong enough. Thus, the PET non-woven support is the main load bearing component which is responsible for the mechanical strength [44]. Furthermore, the membrane used in the module form can lead to sufficient mechanical strength to sustain high pressures.

\subsection{Separation performance of membranes}

Fig. 10 demonstrates the experimental data of PWP, ASPF and ASRE for all substrates and TFC membranes in terms of the WSD loading and PSf concentration. As shown in Fig. 10 (a), PWP decreases by increasing PSf concentration at each loading of WSD. Obviously, this usual trend is related to changes in substrate porosity, pore size, thickness, and hydrophilicity. These results seem 
to be consistent with Ding et al. [2], which found that higher PSf concentration led to a denser layer with thicker skin layer and smaller surface pores. Similarly, Misdan et al. [1] found that the degree of surface hydrophilicity (the surface area corrected interfacial free energy) reduced with increasing polymer concentration, proving that the PWP decline in substrate could be combined effect of increase in water contact angle, pore size and surface roughness. As it can be observed in Fig. 10 (a), the maximum difference among PWP values of substrates with different PSf concentration have been occurred at WSD loading around 0.5 to 1 wt. $\%$. A possible explanation is in pure PSf substrate only the intrinsic properties of polymer determine the PWP. While in MMMs, the interaction between polymer chain and WSD which influence on the pores interconnectivity, porosity, pore size, hydrophilicity, surface roughness and so forth, have influence on PWP. At high loading of WSD, the PWP decreases due to more compact structure of PSf/WSD blend MMM that arises from nanoparticle agglomeration and swelling of the hydrophilic sawdust in the membrane matrix [3]. Another possible explanation is that further increase in WSD loading leading to increase in surface roughness and decline in hydrophilicity.

Fig. 10 (b) illustrates the variation in ASPF of TFC membrane in desalination process versus various concentrations of polymer and sawdust. As can be observed, the maximum ASPF is obtained at concentration in the range of 12 to $14 \mathrm{wt} . \%$ of PSf polymer solution which is highly depended on sawdust loading. There are several possible explanations for these observed results. Firstly, thickness and pore size of the substrate are directly affected by PSf concentration. The porosity and pore size of substrate decrease with increasing polymer concentration [19]. Secondly, the decrease of water flux could be attributed to a lower effective area of PA when denser substrate layer was applied [2]. Thirdly, tight pore structure of the substrate would limit the diffusion of MPD aqueous solution deep into the pores, resulted in formation of thicker PA layer and greater 
surface roughness as evidence in PA contact angle and SEM results [1]. Furthermore, Fig. 10 shows that there has been a marked rise in ASPF by adding a small amount of sawdust into the polymer matrices, particularly at low polymer concentrations. The observed increase in ASPF could be attributed to two main reasons. Firstly, the relatively hydrophobic substrates produced characteristically thicker, rougher, more permeable PA layers. One would expect thicker films to be less dense, and thus more permeable [3]. However, no further increase in ASPF was detected at sawdust loading above 1 wt.\%. As can be seen in Figs. 6 and 7, surface structure and thickness of PA layer have been significantly changed by increasing sawdust loading in the substrate. An excessive increase in the thickness of the PA layer at high concentrations acts as an additional resistance and reduces permeate flux. The other possible reason is reducing hydrophilicity of PA surface with increasing polymer and sawdust concentration.

In the case of ASRE (Fig. 10 (c)), the behavior is relatively similar with ASPF. Salt rejection increased at first and leveled off with the increase of WSD. The interaction between polymer concentration and sawdust loading significantly affected the results. Accordingly, low loadings of sawdust $(\leq 1 \mathrm{wt} . \%)$ for polymer concentration between $12-14 \mathrm{wt} . \%$ not only improve the permeate flux, but also lead to high salt rejection. This might be related to increase in water diffusivity compared with salt diffusivity [45]. Likewise, the reasons leading to an increase in the permeate flux with increasing WSD has been elucidated in preceding paragraph. Those reasons are accountable for increasing the salt rejection rate with the alter in substrate properties.

All in all, adding sawdust at low loading $(\leq 1 \mathrm{wt} . \%)$ as well as low polymer concentration $(<14$ wt.\%) can effectively improve the TFC membrane performance. Consequently, using high values of polymer concentration and sawdust loading are not recommended. Taken together, these results suggest that there is a strong association between TFC membrane performance and porous 
substrate layer characteristics. In reviewing the literature, no data was found on the association between PSf/WSD MMMs and TFC membrane performance. However, a strong relationship between substrate and TFC membrane performance has been reported in prior studies. As explained by Ghosh and Hoek [3], the variance in the surface chemistry and physical structure of PSf substrates produced widely varying PA layer morphology, interfacial properties, and separation performance. They reported that more hydrophobic and rough PSf substrate produced PA layer with higher water permeability, while substrate with large pores produced PA layer with higher salt permeability. 

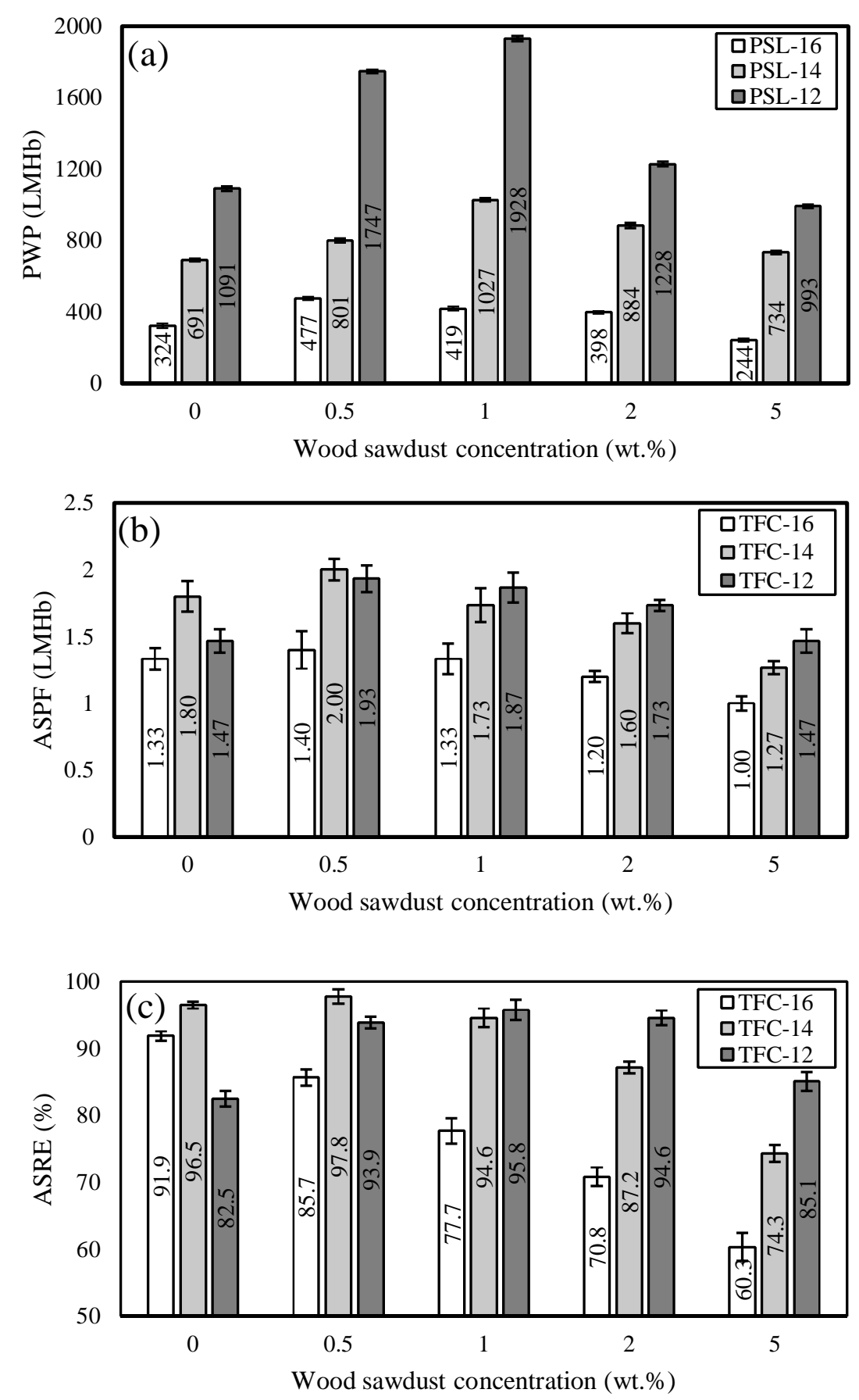

Fig. 10. Separation performance parameters of (a) PSL membranes ( 4 bar, $25^{\circ} \mathrm{C}$, pure water), (b) and (c) TFC membranes (15 bar, $\left.25^{\circ} \mathrm{C}, 2000 \mathrm{ppm} \mathrm{NaCl}\right)$. 


\section{Conclusions and future perspectives}

This research was undertaken to develop a novel MMM and evaluate its performance as the substrate layer of TFC-RO membranes. Accordingly, TFC membranes with different WSD loading and PSf concentration in the substrate were prepared by NIPS and IP methods. To find the appropriate concentration of WSD and PSf polymer in the substrate, the resultant membranes were tested in lab with synthetic saline water and some of them characterized by various analyses. ATRFTIR spectra revealed that the specific functional group of PA with different degree of intensity was able to be detected over all PSf/WSD MMMs regardless of the properties, confirming the successful formation of TFC membrane. Besides, addition of small amount of WSD improved the substrate porosity evidenced by cross-section SEM analysis and PWP. Also, the substrate membrane hydrophilicity, porosity as well as pore size effectively influenced on the TFC membrane permeability. Building upon the results noted above, in this study, we demonstrate that these findings indicate a role for sawdust in promoting TFC membrane performance. In addition, the results support the idea that the separation performance and interfacial properties of TFC RO membranes strongly depends on the properties of substrate layer such as pore structure, pore size, porosity, surface roughness and hydrophilicity. In such a way that highly porous, relatively hydrophobic, and small pores substrates produced more permeable TFC membrane. Overall, it is concluded that the TFC membrane over MMMs of 12-14 wt.\% PSf and 0.5-1 wt.\% WSD were the optimum substrates by taking into account both ASPF and ASRE. Approximately $11 \%$ and $1.3 \%$ improvement were respectively observed in the permeability and salt retention of the TFC14 membrane when $0.5 \mathrm{wt} . \%$ WSD was used in the preparation of MMM. 


\section{Acknowledgements}

The research team would like to thank Ahlstrom Filtration LLC for donation of the PET membrane support, Toni Väkiparta (laboratory technician, LUT School of Engineering Science) and Liisa Puro (analysis engineer, LUT School of Engineering Science) for helping with analyses.

\section{References}

[1] N. Misdan, W.J. Lau, A.F. Ismail, T. Matsuura, Formation of thin film composite nanofiltration membrane: Effect of polysulfone substarte characteristics, Desalination 329 (2013) 9-18.

[2] C. Ding, J. Yin, B. Deng, Effects of polysulfone (PSf) support layer on the performance of thin-film composite (TFC) membranes, J. Chem. Proc. Eng. 1 (2014) 1-8.

[3] A.K. Ghosh, E.M.V. Hoek, Impacts of support membrane structure and chemistry on polyamide-polysulfone interfacial composite membranes, J. Membr. Sci. 336 (2009) 140-148.

[4] G.Z. Ramon, M.C.Y. Wong, E.M.V. Hoek, Transport through composite membrane, part 1: Is there an optimal support membrane?, J. Membr. Sci. 415-416 (2012) 298-305.

[5] M.E. Yakavalangi, S. Rimaz, V. Vatanpour, Effect of surface properties of polysulfone support on the performance of thin film composite polyamide reverse osmosis membranes, J. Appl. Polym. Sci. 134 (2016) 44444-44454.

[6] M.F. Jimenez-Solomon, P. Gorgojo, M. Munoz-Ibanez, A.G. Livingston, Beneath the surface: Influence of supports on thin film composite membranes by interfacial polymerization for organic solvent nanofiltration, J. Membr. Sci. 448 (2013) 102-113.

[7] E.M.V. Hoek, A.K. Ghosh, X. Huang, M. Liong, J.I. Zink, Physical-chemical properties, separation performance, and fouling resistance of mixed-matrix ultrafiltration membranes, Desalination 283 (2011) 89-99. 
[8] D. Qadir, H. Mukhtar, L. Kok Keong, Mixed matrix membranes for water purification applications, Sep. Purif. Rev. 46 (2017) 62-80.

[9] J. Yin, B. Deng, Polymer-matrix nanocomposite membranes for water treatment, J. Membr. Sci. 479 (2015) 256-275.

[10] M.T.M. Pendergast, J.M. Nygaard, A.K. Ghosh, E.M.V. Hoek, Using nanocomposite materials technology to understand and control reverse osmosis membrane compaction, Desalination 261 (2010) 255-263.

[11] G.S. Lai, W.J. Lau, P.S. Goh, A.F. Ismail, N. Yusof, Y.H. Tan, Graphene oxide incorporated thin film nanocomposite nanofiltration membrane for enhanced salt removal performance, Desalination 387 (2016) 14-24.

[12] E.S. Kim, G. Hwang, M. Gamal El-Din, Y. Liu, Development of nanosilver and multi-walled carbon nanotubes thin-film nanocomposite membrane for enhanced water treatment, J. Membr. Sci. 394-395 (2012) 37-48.

[13] M.M. Pendergast, A.K. Ghosh, E.M.V. Hoek, Separation performance and interfacial properties of nanocomposite reverse osmosis membranes, Desalination 308 (2013) 180-185.

[14] S. Bose, C. Das, Sawdust: From wood waste to pore-former in the fabrication of ceramic membrane, Ceram. Int. 41 (2015) 4070-4079.

[15] J. Miao, Y. Yu, Z. Jiang, L. Tang, L. Zhang, Partial delignification of wood and membrane preparation using a quaternary ammonium ionic liquid, Sci. Rep. 7 (2017) 1-12.

[16] G.D. Vilakati, E.M.V. Hoek, B.B. Mamba, Probing the mechanical and thermal properties of polysulfone membranes modified with synthetic and natural polymer additives, Polym. Test. 34 (2014) 202-210. 
[17] G.D. Vilakati, M.C.Y. Wong, E.M.V. Hoek, B.B. Mamba, Relating thin film composite membrane performance to support membrane morphology fabricated using lignin additive, J. Membr. Sci. 469 (2014) 216-224.

[18] G.D. Vilakati, E.M.V. Hoek, B.B. Mamba, Investigating the usability of alkali lignin as an additive in polysulfone ultrafiltration membranes, BioRes. 10 (2) (2015) 3079-3096.

[19] H. Azizi Namaghi, A. Haghighi Asl, M. Pourafshari Chenar, Identification and optimization of key parameters in preparation of thin film composite membrane for water desalination using multi-step statistical method, J. Ind. Eng. Chem. 31 (2015) 61-73.

[20] M. Namvar-Mahboub, M. Pakizeh, Development of a novel thin film composite membrane by interfacial polymerization on polyetherimide/modified $\mathrm{SiO}_{2}$ support for organic solvent nanofiltration Sep. Purif. Technol. 119 (2013) 35-45.

[21] M. Amirilargani, E. Saljoughi, T. Mohammadi, Effects of Tween 80 concentration as a surfactant additive on morphology and permeability of flat sheet polyethersulfone (PES) membranes, Desalination 249 (2009) 837-842.

[22] V. Vatanpour, S.S. Madaeni, A.R. Khataee, E. Salehi, S. Zinadini, H. Ahmadi Monfared, $\mathrm{TiO}_{2}$ embedded mixed matrix PES nanocomposite membranes: Influence of different sizes and types of nanoparticles on antifouling and performance, Desalination 292 (2012) 19-29.

[23] C.Y. Tang, Y.N. Kwon, J.O. Leckie, Effect of membrane chemistry and coating layer on physiochemical properties of thin film composite polyamide RO and NF membranes I. FTIR and XPS characterization of polyamide and coating layer chemistry, Desalination 242 (2009) 149-167. [24] S. Belfer, R. Fainchtain, Y. Purinson, O. Kedem, Surface characterization by FTIR-ATR spectroscopy of polyethersulfone membranes-unmodified, modified and protein fouled, J. Membr. Sci. 172 (2000) 113-124. 
[25] D. Emadzadeh, W.J. Lau, M. Rahbari-Sisakht, H. Ilbeygi, D. Rana, T. Matsuura, A.F. Ismail, Synthesis, modification and optimization of titanate nanotubes-polyamide thin film nanocomposite (TFN) membrane for forward osmosis (FO) application, Chem. Eng. J. 281 (2015) $243-251$.

[26] W. Xie, G.M. Geise, B.D. Freeman, H.S. Lee, G. Byun, J.E. McGrath, Polyamide interfacial composite membranes prepared from m-phenylene diamine, trimesoyl chloride and a new disulfonated diamine, J. Membr. Sci. 403-404 (2012) 152-161.

[27] B.M. Ganesh, Arun M. Isloor, A.F. Ismail, Enhanced hydrophilicity and salt rejection study of graphene oxide-polysulfone mixed matrix membrane, Desalination 313 (2013) 199-207.

[28] G.L. Jadav, P.S. Singh, Synthesis of novel silica-polyamide nanocomposite membrane with enhanced properties, J. Membr. Sci. 328 (2009) 257-267.

[29] M. Fathizadeh, A. Aroujalian, A. Raisi, Effect of added NaX nano-zeolite into polyamide as a top thin layer of membrane on water flux and salt rejection in a reverse osmosis process, $\mathrm{J}$. Membr. Sci. 375 (2011) 88-95.

[30] Z. Yang, J. Yin, B. Deng, Enhancing water flux of thin-film nanocomposite (TFN) membrane by incorporation of bimodal silica nanoparticles, AIMS Environ. Sci. 3 (2) (2016) 185-198.

[31] G.N.B. Barona, J. Lim, M. Choi, B. Jung, Interfacial polymerization of polyamidealuminosilicate SWNT nanocomposite membranes for reverse osmosis, Desalination 325 (2013) $138-147$

[32] L. Ni, J. Meng, X. Li, Y. Zhang, Surface coating on the polyamide TFC RO membrane for chlorine resistance and antifouling performance improvement, J. Membr. Sci. 451 (2014) 205215. 
[33] T.F. Pinto, C.W.B. Bezerra, D.S.A. Silva, E.C. Dasilvafilho, A.P. Vieira, C. Airoldi, J.C.P. Demelo, H.A.S. Silva, S.A.A. Santana, Sawdust derivative for environmental application: chemistry, functionalization and removal of textile dye from aqueous solution, An Acad. Bras. Cienc. 88 (3) (2016) 1211-1220.

[34] W. Gan, L. Gao, X. Zhan, J. Li, Removal of $\mathrm{Cu}^{2+}$ ions from aqueous solution by aminofunctionalized magnetic sawdust composites, Wood Sci. Technol. 51 (1) (2017) 207-225.

[35] A. Shaaban, S.M. Se, M.F. Dimin, J.M. Juoi, M.H.M. Husin, N.M.M. Mitan, Influence of heating temperature and holding time on biochars derived from rubber wood sawdust via slow pyrolysis, J. Anal. Appl. Pyrolysis 107 (2014) 31-39.

[36] V. Saetun, C. Chiachun, S.A. Riyajan, K. Kaewtatip, Green composites based on thermoplastic starch and rubber wood sawdust, Polym. Composites (2015) 1-7.

[37] M. Peyravi, A. Rahimpour, M. Jahanshahi, Thin film composite membranes with modified polysulfone supports for organic solvent nanofiltration, J. Membr. Sci. 423-424 (2012) 225-237 [38] T. Mohammadi, E. Saljoughi, Effect of production conditions on morphology and permeability of asymmetric cellulose acetate membranes, Desalination 243 (2009) 1-7.

[39] Z. Zhang, Q. An, T. Liu, Y. Zhou, J. Qian, C. Gao, Fabrication of polysulfone ultrafiltration membrane of a density gradient cross section with good anti-pressure stability and relatively high water flux, Desalination 269 (2011) 239-248.

[40] J. Park, D. Kim, Effect of polymer solution concentration on the swelling and mechanical properties of glycol chitosan superporous hydrogels, J. Appl. Polym. Sci. 115 (2010) 3434-3441. [41] M.G. Garcia, J. Marchese, N.A. Ochoa, Effect of the particle size and particle agglomeration on composite membrane performance, J. Appl. Polym. Sci. 118 (2010) 2417-2424. 
[42] Y. Ma, F. Shi, Z. Wang, M. Wu, J. Ma, C. Gao, Preparation and characterization of PSf/clay nanocomposite membranes with PEG 400 as a pore forming additive, Desalination 286 (2012) $131-137$

[43] F. Sabeti Dehkordi, M. Pakizeh, M. Namvar-Mahboub, Properties and ultrafiltration efficiency of cellulose acetate/organically modified Mt (CA/OMMt) nanocomposite membrane for humic acid removal, Appl. Clay Sci. 105-106 (2015) 178-185.

[44] H. Ma, K. Yoon, L. Rong, Y. Mao, Z. Mo, D. Fang, Z. Hollander, J. Gaiteri, B.S. Hsiao, B. Chu, High-flux thin-film nanofibrous composite ultrafiltration membranes containing cellulose barrier layer, J. Mater. Chem. 20 (2010) 4692-4704.

[45] S. Tashakkori Iranizadeh, M. Pourafshari Chenar, M. Namvar Mahboub, H. Azizi Namaghi, Impact of support material and hydrophilicity on performance of thin film composite membrane in brackish water desalination, $12^{\text {th }}$ International Conference on Membrane Science and Technology (MST), 2015, Tehran, Iran. 